\title{
Application of Computational Tools to Support Cooperative Learning in Bioreactor Design Course
}

\author{
https://doi.org/10.3991/ijet.v16i15.23697 \\ Muhd Nazrul Hisham Zainal Alam( $\left.{ }^{\bowtie}\right)$, Zaki Yamani Zakaria \\ Universiti Teknologi Malaysia, Johor, Malaysia \\ nazrulhishameutm.my
}

\begin{abstract}
Conventional method of teaching Bioreactor Design course are mostly conducted in a teacher-centred manner. This method is inefficient solution for education as compared to more active learning styles which is proven to be more effective in ensuring students to fully comprehend a particular subject. The work presents the use of various computational tools to support the implementation of cooperative learning (CL) methods in Analysis and Design of Bioreactor course. This subject is offered to $3^{\text {rd }}$ year students of ChemicalBioprocess Engineering program in Universiti Teknologi Malaysia. The CL method was implemented to improve student cognitive skills attainment in each of the course learning outcomes. Achievements of student cognitive skills were assessed quantitatively where else effectiveness of the CL method applied were evaluated qualitatively. Results showed that the student performance and attainment of their cognitive skills at thinking level of 'application' has improved at least by $30-40 \%$. Reflection analysis from students indicated that the proposed student-centred teaching method managed to not only increase students understanding on the subject but also nurtured students creativity and enhances their computational skills.
\end{abstract}

Keywords - active learning, cooperative learning, bioreactor, computational tools.

\section{Introduction}

Student-centred learning (SCL) approach has gained increasing attention amongst engineering educators worldwide over the past few years. Contrary to the traditional teacher-centred learning (TCL) method where lecture time is spent with the professor giving lecture whilst students merely listen and watching; SCL methods inspire students to apply learning to various problems and contexts. It provides students with more control over their learning and thus, help students to learn the 'know-how' rather than memorization of facts. Moreover, in SCL, learning process focusses on the diverse learning needs of students as appose to the need to push through the lecture content as previously done via conventional lecture style [1-3]. Students are able to comprehend more since SCL promotes active learning (AL) where in the context of Cone of Learning, students see, hear, say and do what they learn. 
One of the SCL strategies that have been receiving positive responds from the students is cooperative learning (CL). CL is an instructional-strategy learning activity whereby small group of students work together to complete a common task. Important elements for structured CL activities include positive interdependence, interaction, individual accountability, team-work skills and group processing [1-3]. One of the problems that may arise in CL activity is group conflict and division of task. Students need to work together and this does not always happen naturally [4]. Creating a suitable CL scenario that grasps student interest long enough for them to learn something from one another and/or share knowledge in completing the given task often is a challenge for the instructors especially for those who lack of knowledge and training in the subject and CL management [5-7].

This study attempts to report the use of computational tools (software) to support the implementation of CL activity. CL is a useful teaching methodology for development of different cognitive skills [8,9]. To date, not many utilize computational tools to support $\mathrm{AL}$ environment for teaching chemical engineering majors. There were efforts made to incorporate chemical reactor design based knowledge in a board game [1] but not on the extensive use of computational tools especially for CL activity. There was also attempt to use computational tools for game based learning, but not much has been mentioned about instilling cooperative learning [10]. Hence, the proposed approach was implemented in the Analysis and Design of Bioreactor course, which is a core engineering-based course offered to third year students of ChemicalBioprocess Engineering degree program in Universiti Teknologi Malaysia (UTM). Teaching the concept of bioreactor operation and design is not an easy task. Many opt for the classical TCL approach where students were unable to master a higher level of cognitive skills. The main aim of the work are two folds. First is to develop student cognitive skills on the subject to the thinking level of 'application' and 'analysis'. Secondly is to develop student skills in using industrial based software for calculation and analysis of processes related to bioreactor design and operation. Encouraging the student to utilize various software in their learning activity would allow them to directly apply the concept they learn during lectures. It would also assist the student to strategically comprehend the knowledge instead of purely memorizing it.

The CL approach implemented is discussed in detail that include mapping of the course learning outcomes (CLO) to the task given and the level of cognitive skills. Effectiveness of the CL activities were assessed qualitatively (survey, reflection, questionnaire, and observation) while the effectiveness of the CL method applied were evaluated quantitatively (assignments and exams). Additionally, student performance based on the classical TCL and the proposed SCL technique were compared as well. 


\section{$2 \quad$ Application of Design}

\subsection{Course description}

Owing to the industrial importance of bioreactor, the "Analysis and Design of Bioreactor" course has been made as a core subject for the degree of ChemicalBioprocess Engineering program in UTM. It is a 3 credit hours course and offered to the third year students of the program $\left(5^{\text {th }}\right.$ semester $)$. The course emphasizes on bioreactor features and operation, mass balances and kinetics on growth and product formation, mass and heat transfer in bioreactor, mixing and instrumentation of bioreactor operation. The CLO are as follows:

- Explain the features and type of bioreactors (CLO1).

- Apply stoichiometry balances and solve microbial kinetics for bioreactor operation (CLO2).

- Determine the mass and heat transfer requirements of bioreactor system (CLO3).

- Determine mixing requirements and implement scale-up equation for bioreactor operation (CLO4).

- Analyse bioreactor instrumentation and control system (CLO5).

Besides observations, reflection from course instructors and students comments from previous semesters highlighted the following teaching/learning issues associated to this course:

- Students complained that they were unable to understand the fundamental of the course and spent put most effort in memorizing equations.

- Lectures were delivered using conventional TCL method.

- Students only studied to pass tests and/or final exams.

Another pressing issue is that through TCL, cognitive attainment and development of each learning outcomes were not properly evaluated. Student's performance indicators were solely based on the final grade distribution, which hardly reflects the specific CLO achievements.

\subsection{Theoretical Background}

The course is designed based on the principle of Constructive Alignment (CA) $[8,9]$. Via Constructivist Principles, CA affirms that both the teaching and learning activities as well as the assessment tasks must support the development of the learning outcomes among students. To incorporate Constructivist principles, SCL activities were implemented as the teaching and learning approach to learn and solve bioreactor design and application based problem [11]. 


\subsection{Revolutionizing the teaching strategy}

Present data from our own curriculum showed that current teaching plan for this particular course depending mainly on lectures $(80 \%)$ and tutorials/exercises $(20 \%)$. In this work, a new teaching model is presented where teaching and learning activities will combine the classical lecturing technique (30\%) with AL concept (70\%). Deliverable of lectures on the theoretical concept was integrated with series of AL activities such as the pause procedure, think-pair-share, etc. In addition, in the end of every topic, CL activities were implemented to assess student understanding on the lectures given.

CL activities were carried out immediately after completing the lecture on a specific learning outcome. In each session, students were first briefed on the outcome, CL style and how they could benefit further from such learning activity. Then, groups were formed and assigned with a specific task to be completed. Table 1 presents the mapping of the CLO to the task for the CL session, its link to various cognitive skills and assessment methods of each activity.

Table 1. Mapping of course learning outcomes to CL activities

\begin{tabular}{|l|l|c|l|}
\hline CLOs & \multicolumn{1}{|c|}{ CL activity/task } & Cognitive skills & \multicolumn{1}{|c|}{ Cognitive Assessment } \\
\hline CLO1 & 3D drawing via Solidwork & Application & $\begin{array}{l}\text { Task (5\%) } \\
\text { Test 1 (5\%) }\end{array}$ \\
\hline CLO2 & Simulation work via SuperPro designer & Application & $\begin{array}{l}\text { Test 1 (15\%) } \\
\text { Final (10\%) }\end{array}$ \\
\hline CLO3 & Parameter estimation via Matlab & Application & $\begin{array}{l}\text { Test 2 (15\%) } \\
\text { Final (10\%) }\end{array}$ \\
\hline CLO4 & Video analysis of mixing phenomena & Application & $\begin{array}{l}\text { Task (10\%) } \\
\text { Final (10\%) }\end{array}$ \\
\hline CLO5 & Analyze control features via MsVisio & Analysis & $\begin{array}{l}\text { Task (10\%) } \\
\text { Final (10\%) }\end{array}$ \\
\hline & Total & & (100\%) \\
\hline
\end{tabular}

Group formation is one of the essential parts of this CL activity and in order to break student tendency to choose the one sitting next to them as their group members, grouping was sorted-out by the instructor. Each group consisted of a mixture of gender and high/low performers based on their current grade-point-average (GPA). Heterogeneity of each group was ensured by forming the group consisting of students with grade-point-average (GPA) greater than 3.0/4.0 and students with GPA lower than 3.0/4.0. The maximum number of students per group was limited to no more than four students.

\subsection{Description of the task for Cooperative Learning}

Tasks given were to support the learning activity of each learning outcomes and the students were required to use various software (or multi-media elements) to showcase their project output. Details of each of the assignments are as follows: 
CLO1 Task: Students were required to utilize SolidWorks software and produce/sketch a three-dimensional (3D) bioreactor prototype. The drawing should be based on the reactor prototype presented in class. Students were also required to evaluate the geometrical features of the reactor. Assignment will contribute to $5 \%$ of total course work mark.

CLO2 Task: Students were required to solve a stoichiometry equation for an aerobic batch fermentation and apply it using a Superpro Designer software in order to study the kinetics of the process. Students were also required to evaluate the yield and the cells specific growth rate of the process. Assignment is considered as part of the class activity.

CLO3 Task: Students were required to estimate the mass and heat transfer coefficient of the bioreactor operation at a certain agitation and aeration rates using Matlab. Equations describing the mass and heat transfer rates were considered as the ordinary differential equation. Assignment is considered as part of the class activity.

CLO4 Task: Students were required to determine suitable mixing requirements of a bioreactor operation based on a given video. The video was about mixing phenomena in a bioreactor. In addition, students were required to apply suitable scale-up equations to retain the same mixing conditions in a larger reactor platform. Assignment will contribute to $10 \%$ of total course work mark.

CLO5 Task: Students were required to analyse a Process and Instrumentation Diagram (PID) of a bioreactor system. Then, the students need to analyse and redraw the suitable control features for a specific application/process using a bioreactor. Assignment will contribute to $10 \%$ of total course work mark.

Each tasks pertaining to the CL activity were assigned to the same group until the end of the course. This is a form of formative assessment where students performance, individually and as a team were assessed periodically (5 times) throughout the 14 weeks semester. Students received swift feedbacks, occasionally within 1 week from the date they submitted their assignment and this allow them to learn and reflect how they have performed.

\subsection{Evaluation of Cooperative Learning activity}

Main elements of the CL method implemented were assessed in order to evaluate the effectiveness of the method. It was done in the end of each tasks and the evaluation performed are as follows:

- Positive interdependence: Survey card to identify student's individual skills/resources.

- Face-to-face interaction: Conduct group discussion and each group required to submit work plan.

- Individual accountability: Questionnaire card to inquiry student contribution in the task.

- Team-work skills: Peer rating evaluation 
- Group processing: Survey card for students to identify group decision making, observation by instructor, project output and students reflection in e-portfolio webpage.

\section{Results and Discussion}

\subsection{Students output and instructor observation}

Our observation shows that the students did not hesitate to engage in a CL mode once we initiated the activity. Upon receiving the task from the instructor (in this case the course lecturer), students immediately interacted and plan their working schedule prior to complete the task given. They shared with one another about their own skills/expertise and discussed amongst the group member on the best method to complete each of the assignments -showing a clear positive interdependences quality and capacity to actively interact with other group members. Clearly, their experiences in AL environment in their first year course (Introduction to Engineering) seemed to pay off $[12,13]$. They understood the kind of commitments needed in such learning activity and they knew early on that the only way to benefit from it is by participating.

One of the challenges face by the students are incompetency in using different computational tools in meeting the requirement of each tasks. This is indeed worrying especially considering that each assignment is closely associated to the course learning outcomes. Each group needs to master it or at least learn the basic functionality of each software prior to complete every task given. In spite of this, the students remained highly motivated. Apart from the guidance provided by the instructor via eLearning, the student also took the initiatives to learn more about the software from various open sources.

Evidence of the student participation in the first CL session is depicted in Figure 1. The task assigned for CLO1 required the students not only to learn about SolidWorks and basic bioreactor features but also to analyse the drawing produced and presented it with proper dimensioning. SolidWorks is a three-dimensional (3D) computer aided design software typically used for prototyping of product design prior to machining/fabrication. Although majority of the students (i.e. > 80\%) did not have any idea on how to use SolidWorks software but the implementation of the CL method has enabled them to learn it with very minimal supervision. This is totally opposite to what was done in the previous teaching plan where student merely listening to lecture about the definition of bioreactor in general. Moreover, student will have the opportunity to practice the knowledge they attained in the first year of their program about the fundamental of engineering drawing.

In the second CL activity (CLO2), students were trained to use the SuperPro Designer software. It is an interactive process simulator generally applied to simulate biotechnological based processes $[14,15]$. The exercise offered a platform for the student to model a bioreactor operation at various conditions. There is no limit to the type of biological conversion that can be simulated in this activity. Moreover, solution to each elemental balance performed in solving the stoichiometry equation for the 
fermentation processes is evaluated not by looking for the answers in the back of a textbook but through validation of a real biological process that was simulated using the SuperPro Designer software. Another benefit of this exercise is that the student will gain knowledge on process scheduling - a feature that is available in the SuperPro Designer software where students could learn to visualize the scheduling of the process they simulated by analysing the equipment utilization charts. Example of the student output from this exercise is presented in Figure 2.
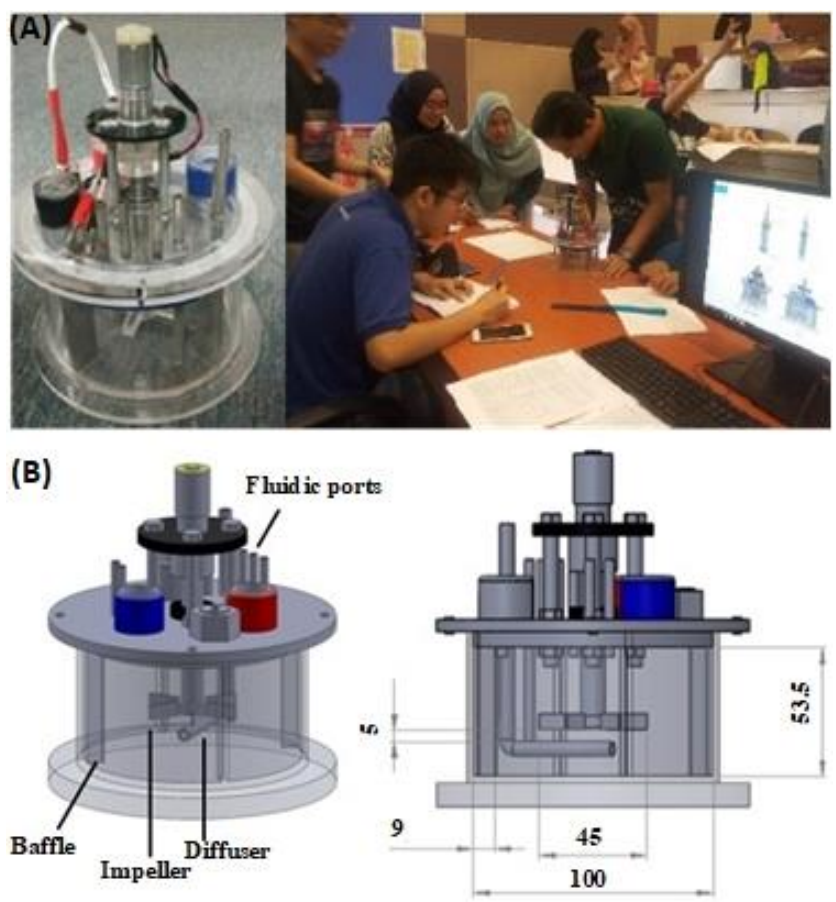

Fig. 1. Picture of the mini bioreactor prototype assigned for the task (left). Image indicating students participation in the first CL activity (right). B) Drawings produced via SolidWorks (CLO1) and edited in Microsoft Visio software.

The third CL session was formulated to train the students about the impact of operating variables on the reactor mass and heat transfer rates (CLO3). A set of experimental data about the topic were provided to each group and they were required to estimate the mass and heat transfer coefficients using the Matlab software. Matlab is a multi-paradigm numerical computing software and the student have already learnt about it in one of their second year courses. The learning activity gave student the chance to study about the concept of bioreactor mass and heat transfer rates using a real experimental data. Since the student had a week to complete the task, this had given them more than enough time to reminisce and apply suitable mathematical algorithms using Matlab in order to meet the requirements of the assignment for CLO3. Example of the student output from this activity is shown in Figure 3. 

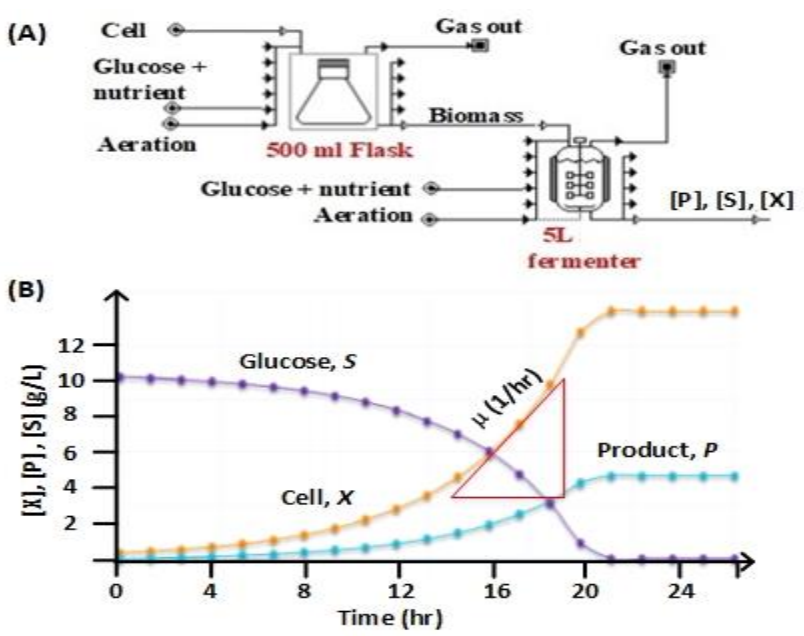

Fig. 2. Example of the output from CL activities for CLO2. A) Process flow sheeting of a bioreactor operation for a batch fermentation process. B) Results of the student simulation where they cooperatively learnt about the fermentation kinetics.

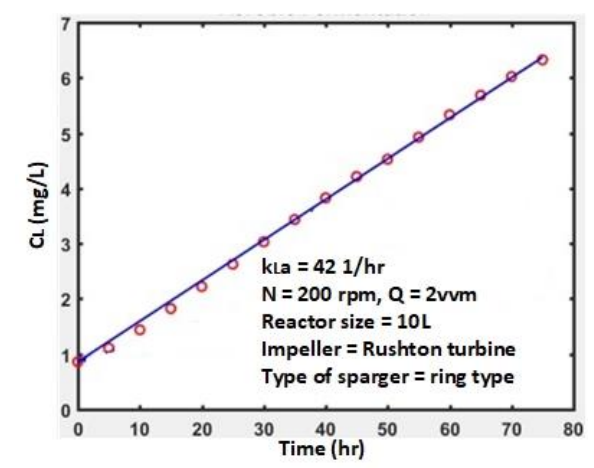

Fig. 3. Result from one of the group on the estimation of bioreactor mass transfer coefficient, kLa using Matlab software.

In the subsequent CL activity (CLO4), teaching and learning activity was supported with the use of videos. Videos of actual events associated to mixing in a bioreactor were created and presented to the students. The inclusion of video changed the mood of the learning environment and transformed the students into a more active learners. A task were assigned to each group where they had to analyse the video and correlated it with theory they learnt from the lecture. Students were indeed very resourceful and have successfully produced an insightful image analysis from the activity. Additionally, they cooperatively learnt on how to evaluate the reactor optimal mixing conditions at different scale of operation. Results attained from this activity is shown in Figure 4.

The task of the final CL activity (CLO5) encouraged the student to draw a process and instrumentation diagram (P\&ID) for a specific bioreactor operation using Mi- 
crosoft Visio software, which has already been introduced to students in their first year. A P\&ID is a diagram that illustrates the interconnectivity of the process equipment and the sensors and actuators utilized to control that process [16,17]. It is indeed a useful skill to learn for any future process engineer. Additionally, this activity will enable the student to gain a comprehensive overview of all the control features of a bioreactor system as they will have to analyse their P\&ID sketch and justify the objective of every control loop of the bioreactor. The learning outcome for this activity was met through actual practice as an engineer and this somewhat had driven the student to work on the CLO5 task enthusiastically. Example of the results achieved in CLO5 activity is presented in Figure 5.

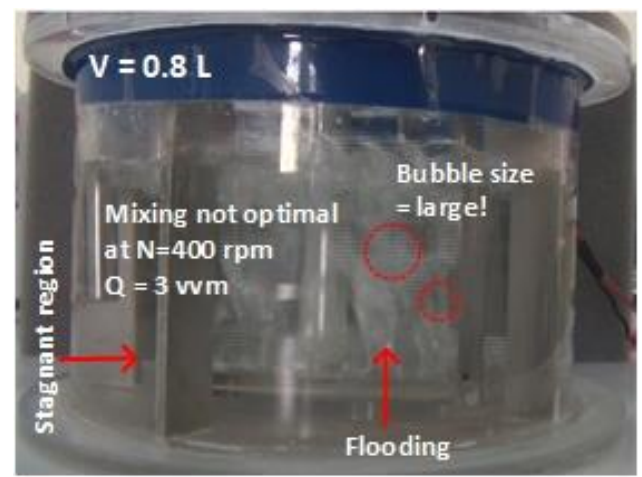

Fig. 4. Results of the image analysis about mixing events in a lab scale bioreactor. The image was produced by one of the group using the Kinovea and Microsoft Visio software.

The results and the quality of work produced by the students was astonishing. Not only that they completed every tasks within the given time frame but they also utilized other various types of computational tools to make their output more presentable. Incompetency or lack of experience in using the required computational tools was never any issue. It did not cause any inconveniency or conflict to the students. Clearly, by bringing the students into the environment they are comfortable in (i.e., working in groups), it will promote enjoyable learning environment and nurture their creativity.

\subsection{Cooperative Learning Impact}

$\mathrm{CL}$ is an instructional teaching model whereby students cooperate with one another to achieve a same objective [18-20]. Working together often improved the end result; nevertheless, each of the students are accountable for their own achievement. In order to evaluate the contribution from each member of the group, we had the students to complete a survey card to share their work plan and commitments from each member of the group. This method would make the student aware of the fairness of such CL activity. Additionally, peer rating evaluation was also carried out so that student could grade their colleague's contribution. 


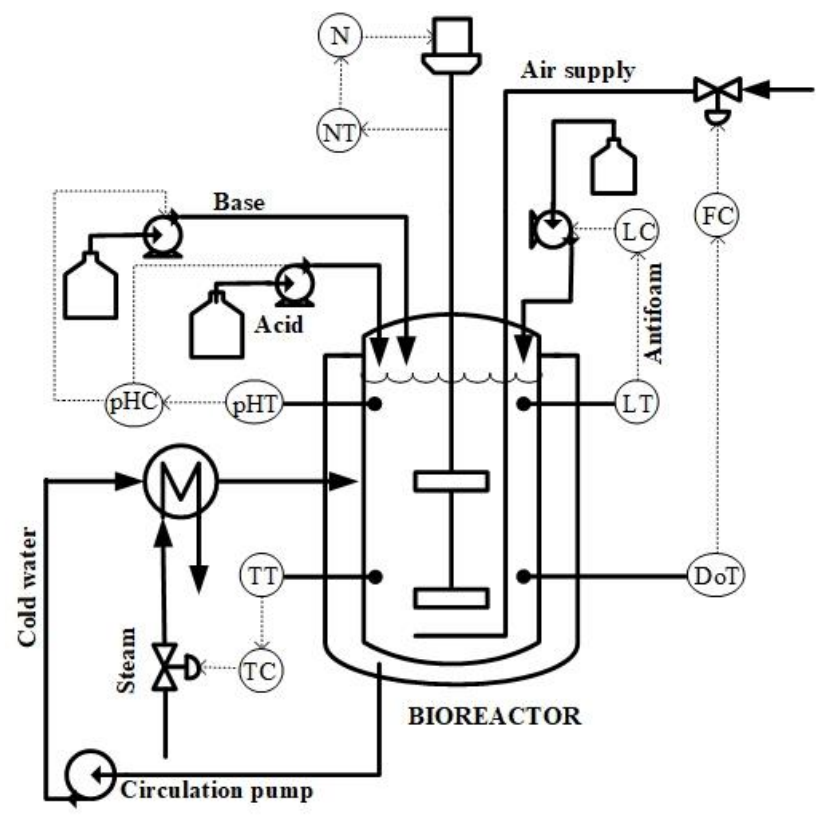

Fig. 5. One of the process and instrumentation diagram produced by the student using the Microsoft Visio software in the CLO5 learning activity.

The present work was implemented in academic session 2019/2020-I, where 54 students were registered for the course and thus, allowed us to form 18 groups for the $\mathrm{CL}$ activities. Figure $6 \mathrm{a}$ depicts the statistical data of student contribution on the task given - data presented as average contribution by each student. Each group consisted of 3 students and for every assignment given, contribution of each member of the group were divided into several tasks namely learning the software, solving the problem, and report writing. Our survey showed that $60 \%$ of the student assisted on two of the tasks at hand where else nearly $25 \%$ of them involved on every aspect of the assignment. Interestingly, our analysis also discovered that student with grade-pointaverage (GPA) of $2.75 / 4.00$ or greater seemed got involved and/or contributed to at least two tasks prior to completing the assignment given (Figure $6 \mathrm{~b}$ ).

This statistic is a measure of student commitments and their willingness to participate in such CL environment. It was noticeable that low academic achievers (i.e. the one with GPA less than 2.75) did feel a bit inferior in the beginning of the exercise. Such emotion was probably caused by the fact that there is not much that they can help with in each assignment. Nonetheless, that mentality changes through the CL environment where they had a chance to improve their capability/skills through active discussion and interaction with their group members. They took the initiative to adjust to the situation and felt that there are other aspect of the assignment that they can contributed on. Data from the survey analysis reflected our observation where there are no passive learners in each group during the execution of the CL activity. 
(A)

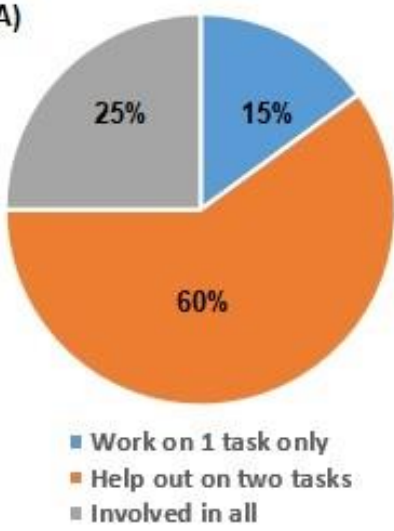

(B)

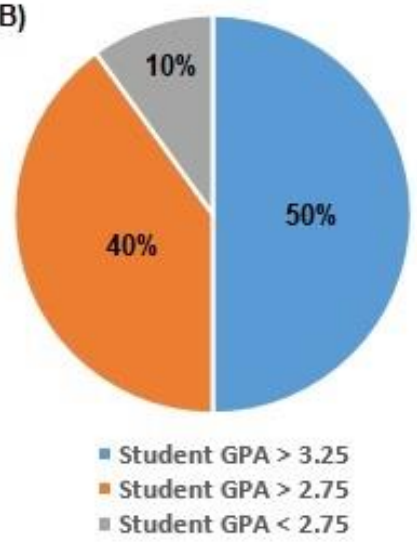

Fig. 6. A) Statistical data summarizing student overall contribution on each CL activities. Data is presented as average contribution by each student. B) Percentage of student that involved in at least two tasks or more in each assignment.

Upon completion of all of the assignments, students were required to answer questionnaires and give some reflection of what they had learnt thorough-out the task given. Figure 7 presents the summary of the general survey asked to the students. The students were asked about their opinion on the manner of how they completed the task given and did the task provided had spark any creativity within themselves whilst working on it. According to the survey, it was found that not all of the assignment/tasks given required a full collaboration from each member of the group. Except for the activity from CLO2 and CLO3, every respondents completed the task as a team and two third of them strongly agreed on the fact that the task given could only be completed through teamwork. Furthermore, majority of the students (i.e. more than $>70 \%$ ) that responded to the survey agreed that the assignment given had inspired them to be creative. It is believed that the nature of the assignment in each topic may have affected the obtainment of these values (team working and creativity).

From the technical point of view, producing a 3D drawing of a bioreactor in CLO1 activity do require one to assemble various types of parts together [21]. Clearly, the students did figure this out and perhaps had even delegated the task equally amongst the group members. Final assembly of the parts drawn by each student is indeed a challenging part of the assignment. One can only do this through face-to-face interaction as they need to decide which part goes first (or where) and be creative about it as well. This is because the final assembly of the reactor must meet the general guideline of a typical reactor design. Similar things can be said for activity in CLO5 where it required them to do some critical thinking and analysis before completing the task. In the end, it was not simply about putting different pieces together, it was also about interaction, team-working and creative thinking. This is however may not be the case for activity formulated for CLO2 and CLO3 where the solution requires each group to perform series of computation and solving of various equations. In this situation, passive students will tend only to their own tasks in each assignment and knowledge 
on the topic given is gained through peer teaching. Moreover, creative response was clearly seen amongst the student only when they were working with something a bit more complex than number crunching such as activity in CLO1, CLO2 and CLO5. This explained why there were a small number of students who thought that activity for CLO3 and CLO4 somehow did not help to explore their creativity.

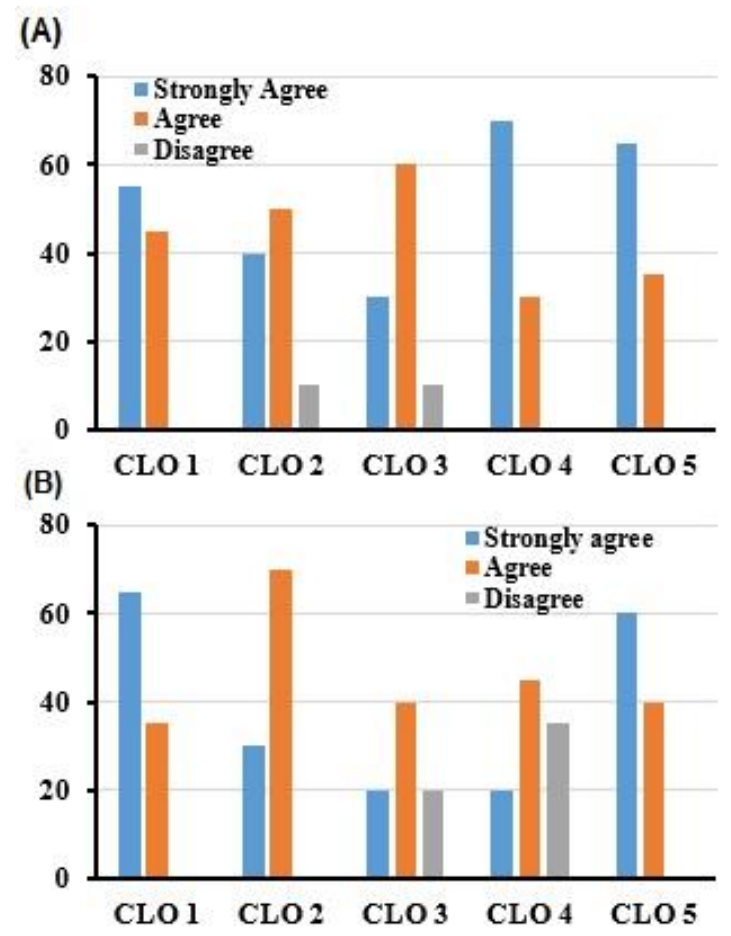

Fig. 7. General survey to the students about (A) the need for team-working in completing the task given and (B) if task given had nurtured student creativity.

\subsection{Quantitative assessment on development of cognitive skills}

Attainment of student cognitive skills from the CL activity conducted was evaluated quantitatively. This was done through assignment and exams. Student performance was also compared with the results from the previous semester where teaching and learning activity was still based on the classical teacher-centred learning method. Table 2 summarizes the most recent student performance between 2017 and 2019. Performance was based on the average score attained by the students for each of the learning outcomes. As shown in Table II, average score by the students were almost similar in 2017 and 2018. Student score for CLO2, CLO4 and CLO5 were slightly below par (i.e. $\leq 60 \%)$. The trend however changes upon switching to the AL teaching model. Overall score for each learning outcomes improved significantly especially for CLO4 and CLO5. 
Table 2. Comparison of student performance between different teaching methodologies based on the average score for each learning outcomes

\begin{tabular}{|l|c|c|c|}
\hline CLOs & Teacher centred (2016/2017-I) & Teacher centred (2017/2018-I) & $\begin{array}{c}\text { Student centred } \\
(\mathbf{2 0 1 8 / 2 0 1 9 - I )}\end{array}$ \\
\hline CLO1 & $76 \%$ & $73.9 \%$ & $81.3 \%$ \\
\hline CLO2 & $54 \%$ & $58 \%$ & $68.2 \%$ \\
\hline CLO3 & $72 \%$ & $77 \%$ & $81 \%$ \\
\hline CLO4 & $58 \%$ & $46.5 \%$ & $82 \%$ \\
\hline CLO5 & $61 \%$ & $60 \%$ & $78.5 \%$ \\
\hline
\end{tabular}

Clearly, those who participated in the AL activity would produce a more quality assignment and performed better in examinations. In the previous teaching plan, student generally work on the exercise given to them on their own. Some did not even do any exercises and simply memorized the content of the lecture. In CL environment, students were encouraged to work in group and consequently such small-group learning improved their academic achievements. Since the same group was retained for each tasks given, each member of the group would receive continuous support and all the assistance needed from their peers to keep progressing academically. Student cognitive skills slowly developed from receiving the knowledge from the instructor (lecturing) to comprehension phase (discussion with peers and instructor) and finally ability to apply/analyse the concept being taught from the lecture (assignments in CL session).

Furthermore, in our CL activity, students were given the opportunity to improve their competency in utilizing industrial based computational tools. Some of the software proposed for the CL activities such as SolidWorks, SuperPro Designer and Microsoft Visio are not only useful for their final year project but also valuable in various engineering field. Given the significance of such tools for their future benefit, the student became highly motivated to learn and master each of the software used in the work. Some even considered themselves as an expert user of the software. This is a fact as our observation showed that a small number of students voluntarily shared their technical skills on the software with the instructor of the course after completing the task. It is believed that a good relation between the instructor and the students is important during this sort of learning activity as it will spark student initiatives to share their knowledge not only with their peers but also with the teacher who inspired them. Research showed that average students tend to forget $70 \%$ of what they learned over a period of 24-48 hours [22-24]. By directly applying the knowledge they gained in the lecture, theoretical concept can be better understood and knowledge gained can be retained and not forgotten. Explanation of lecture materials through peer-teaching also help student to remember information transferred during lecture and relate it to existing knowledge.

Table 3 displays some of the reflections collected from the students upon in the end of the course. They claimed that CL activity have helped them to understand the lectures about the subject and given them the opportunity to learn about using specific computational tools. They also collectively agreed that such CL experience had encourage them to work with others and this has improved their communication skills and push them to the limit where they became motivated to complete the task given by exceeding the lecturer expectations. 
Table 3. Selected reflections of the students that participated in the CL Activity

\begin{tabular}{|l|l|}
\hline \multicolumn{1}{|c|}{ Respondents } & \multicolumn{1}{c|}{ Reflection } \\
\hline Respondent 1 & $\begin{array}{l}\text { These activities give me chances to read and learnt more for the task given. I have } \\
\text { learnt and shared with my friends; skills and techniques about how to draw using } \\
\text { SolidWorks. The assignment forces me to watch video not only to entertain myself } \\
\text { but also to explore new knowledge. }\end{array}$ \\
\hline Respondent 2 & $\begin{array}{l}\text { Learning to use some of the software is sometimes challenging. Luckily, I received } \\
\text { numerous help from my colleague. Group learning environment do really help me } \\
\text { to succeed. }\end{array}$ \\
\hline Respondent 3 & $\begin{array}{l}\text { The learning activity carried out in the class is useful and exciting. It helps us } \\
\text { engage our friends and focus more on the lecture. It encourages us to look for more } \\
\text { info during and after lecture time. It stimulates me in terms of creativity and push } \\
\text { me to be better than others. }\end{array}$ \\
\hline
\end{tabular}

\section{Conclusion}

CL method was successfully implemented where the technique was employed with the use of various computational tools. Students responded positively to the task given and such activity has helped them to understand the subject better. Students gained not only knowledge but also skills on computational tools that are highly relevant in the field of chemical engineering. Moreover, the activity had stimulated students' creativity and willingness to share the knowledge gained. These qualities help to develop student cognitive skills and therefore, allowed them to perform better academically.

\section{Acknowledgement}

This project was funded by the Fundamental Research Grant Scheme of Minister of Higher Education of Malaysia (FRGS/1/2019/TK02/UTM/02/9).

\section{$6 \quad$ References}

[1] Azizan, M.T., Mellon, N. Ramli, R.M., Yusup, S. (2018). Improving teamwork skills and enchancing deep learning via development of board game using cooperative learning method in Reaction Engineering course. Education for Chemical Engineers. 22, pp. 1-13. https://doi.org/10.1016/j.ece.2017.10.002

[2] Johnson, D.W., Johnson, R.T. (2009). An Educational Psychology Success Story: Social Interdependence Theory and Cooperative Learning. Journal of Educational researcher. 38(5), pp. 365-379. https://doi.org/10.3102/0013189x09339057

[3] Ballesteros, M.A., Sanchez, J.A., Ratkovich, N., Reyes, L.H. (2020). Modernizing the chemical engineering curriculum via a student-centered framework that promotes technical, professional, and technology expertise skills: the case of Unit Operations. Education for Chemical Engineers. 35. https://doi.org/10.1016/j.ece.2020.12.004

[4] Nawi, N.D., Phang, F.A., Yusof, K.M., Rahman, N.F.A., Zakaria, Z.Y., Hassan, S.A.H.S., Musa, A.N. (2019). Instilling Low Carbon Awareness through Technology-Enhanced Co- 
operative Problem Based Learning. International Journal of Emerging Technologies in Learning. 14(24), pp. 152-166. https://doi.org/10.3991/ijet.v14i24.12135

[5] Laal, M., Khattami-Kermanshahi, Zh. (2012). 21st century learning; learning in collaboration. Journal of Procedia - Social and Behavioral Sciences. 47, pp. 1696 - 1701. https:// doi.org/10.1016/j.sbspro.2012.06.885

[6] Laal, M. (2013). Positive interdependence in collaborative learning. Procecia - Social and Behavioral Sciences. 93, pp. 1433 - 1437. https://doi.org/10.1016/j.sbspro.2013.10.058

[7] Arteaga, J.F., Blanco, M.J.D., Fuentes, C.M. Alfonso, J.E.M. (2013). Implementation of a cooperative methodology to develop organic chemical engineering skills. European Journal of Engineering Education. 38(4): pp. 370-384. https://doi.org/10.1080/03043797. $\underline{2013.767779}$

[8] Booysen R., Grosser, M. (2014). The effect of cooperative learning on the thinking skills development of foundation phase learners. Education as change. 18, pp. 47-71. https://doi .org/10.1080/16823206.2013.847010

[9] Hoorani, B.H. (2014). Impact of cooperative learning in developing students cognitive abilities for academic achievement. Journal of Education and Educational Development. 1(2): pp. 145-155. https://doi.org/10.22555/joeed.v1i2.41

[10] Alam, M.N.H.Z. (2020). Arduino for Chemical Engineering Students via Game-based Learning. ASEAN Journal for Engineering Education. 4(1), pp. 19-30.

[11] Biggs J., Tang, C. (2007). Teaching for Quality Learning at University 3rd ed. Open University Press, London, United Kingdom.

[12] Wink, D.J. (2020). Chemistry Education and the Post-constructivist Perspective of Bruno Latour. Journal of Chemical Education. 97(12): pp. 4268-4275. https://doi.org/10.1021/ acs.jchemed.0c00263

[13] Sadikin, A.N., Yusofa, K.M., Aziza, A.A., Hassim, M.H., Zakaria, Z.Y., Mustaffa, A.A., Hamid, M.K.A. (2017). A Multi-Year Study of Professional Skills Development among First Year Chemical Engineering Students. Chemical Engineering Transaction. 56, pp. 1453-1458.

[14] Sadikin, A. N., Mohd-Yusof, K, Phang, F.A., Abdul Aziz, A. (2019). The introduction to engineering course: A case study from Universiti Teknologi Malaysia. Education for Chemical Engineers. 28, pp. 45-53. https://doi.org/10.1016/j.ece.2019.04.001

[15] Argo, E., Keshwani, D.R. (2019). Techno-economic implications of fed-batch enzymatic hydrolysis. Processes. 7(11), 847. https://doi.org/10.3390/pr7110847

[16] Petrides, D., Carmichael, D., Siletti, C., Koulouris, A. (2014). Biopharmaceutical process optimization with simulation and scheduling tools. Bioengineering. https://doi.org/ 10.3390/bioengineering1040154

[17] Saygili, Y., Kincal, S., Eroglu, I. (2015). Development and modeling for process control purposes in PEMs. International Journal of Hydrogen Energy. 40 (24), pp. 7886-7894. https://doi.org/10.1016/j.ijhydene.2014.10.116

[18] Siddiquia N.A., Mindeb, N., Mondala, P., Vijayakumar, A.K. (2015). Study of P\&ID, safeguarding philosophy, design basis and its features. International Journal on Occupational Health \& Safety, Fire \& Environment - Allied Science. 3. pp. 1-6.

[19] Chen, F-S., Ke, H-S., Chen, Y-C. (2020). Online Learning as a Panacea? An Empirical Study to Discuss Problem-Based Cooperative Learning in Taiwan.International Journal of Emerging Technologies in Learning 15(18), pp. 251-259. https://doi.org/10.3991/ijet. v15i18.15079

[20] Chan, K.K., Zhou, Y.C. (2020). Effects of Cooperative Learning with Dynamic Mathematics Software (DMS) on Learning Inversely Proportional Functions. International Journal of 
Emerging Technologies in Learning. 15(20), pp. 210-225. https://doi.org/10.3991/ijet. v15i20.14339

[21] Gleason, B.L., Peeters, M.J., Resman-Targoff, B.H., Karr, S., McBane, S., Kelley, K., Thomas, K., Denetclaw, T.H. (2011). An active-learning strategies primer for achieving ability-based educational outcomes. American Journal of Pharmaceutical Education. 75(9), pp. 1-12. https://doi.org/10.5688/ajpe759186

[22] Li, S. (2016). Modeling and Simulation Research of Ball End Mill Rake Face. Chemical Engineering Transactions. 51: pp. 1237-1242.

[23] Bacon, D. R., Stewart, K. A. (2006). How fast do students Forget What they learn in consumer behavior? A longitudinal study. Journal of Marketing Education. 28(3), pp. 181192. https://doi.org/10.1177/0273475306291463

[24] Donald, T.W., Vilceanu, M.O. (2011). The new science of learning and why students forget their economics so quickly. DETU Working Papers 1104. Department of Economics, Temple University.

\section{Authors}

Muhd Nazrul Hisham Zainal Alam is a senior lecturer in the School of Chemical \& Energy Engineering, UTM. His area of expertise includes design and operation of bioreactor system, process automation and fermentation technology. He received his $\mathrm{PhD}$ degree in the field of Chemical Engineering in Denmark Technical University (DTU) in 2011. He spent nearly 4 years in Deakin University, Geelong Australia between 2013 and 2017 as a post-doctoral fellow where he focused mainly on process automation and microfluidics technology. Presently, he has over 60 hours teaching experience and has published nearly 45 ISI/Scopus indexed papers, book chapters and academic proceedings.

Zaki Yamani Zakaria is from the School of Chemical \& Energy Engineering, Faculty of Engineering, UTM and the Director for Centre for Engineering Education (CEE), UTM. His main research interests are in engineering education, catalytic reaction engineering, green related technology, and safety and health. Previously, he practiced as a Project Engineer (2003-2005) and Process Engineer (2005-2008). Dr. Zaki has published more than 100 international publications in various journals, conferences and book chapters. Since 2017, under CEE UTM, he has assisted to handle more than 25 workshops related Active Learning, Cooperative Learning, Problem Based Learning and Outcome Based Education.

Article submitted 2021-05-03. Resubmitted 2021-06-17. Final acceptance 2021-06-18. Final version published as submitted by the authors. 